Pedagogía y Saberes n. ${ }^{\circ} 52$

Universidad Pedagógica Nacional

Facultad de Educación. 2020. pp. 117-129

\title{
El alcance limitado de la resocialización como educación carcelaria*
}

Artículo de reflexión

The Limited Reach of Resocialization as Penitentiary Education

$\bigcirc$ alcance limitado da ressocialização como educação carcerária

Óscar Antonio Ramírez Rojas**

Para citar este artículo:

Ramírez, O. (2020). El alcance limitado de la resocialización como educación carcelaria. Pedagogía y Saberes, 52, 117-129. DoI: https://doi.org/10.17227/pys.num52-9555

* El presente artículo de reflexión retoma una de las conclusiones de la investigación "Un sujeto, su entorno y la cárcel", en el marco de la Maestría en Estudios Sociales de la Universidad Pedagógica Nacional concluida en 2016.

** Profesor de la Fundación Educación por el Respeto y magister en Ciencias Sociales de la Universidad Pedagógica Nacional de Colombia.

Correo electrónico: oaramirezr@gmail.com

Código ORCID: https://orcid.org/0000-0002-6875-9983 


\title{
Resumen
}

Este artículo es una reflexión sobre lo contradictorio del programa de resocialización aplicado por el Instituto Nacional Penitenciario y Carcelario (Inpec) en las cárceles colombianas. Dicha reflexión nace de un estudio de caso desarrollado en la Penitenciaría Central La Picota, de la ciudad de Bogotá, con una persona que estuvo condenada a la privación de la libertad, en uno de sus patios, y se alimenta de los desarrollos investigativos sobre el fenómeno carcelario. Se aborda también la influencia que la educación tiene en la formación de la subjetividad y sobre lo fundamental e influyente de los contextos en lo educativo. Se muestra cómo parte de las causas del delito común es la falta de cobertura educativa y promoción de oportunidades por parte del Estado. Por último, se detiene en la conceptualización teórica de la subjetividad a partir de tres autores para mostrar que los espacios carcelarios determinan una variante que ha sido poco desarrollada.

\section{Palabras clave}

delito; subjetividad; educación; cárcel; resocialización

\begin{abstract}
This article is a reflection on the contradictory aspects of the resocialization program implemented by the Instituto Nacional Penitenciario y Carcelario (Inpec) in Colombian prisons. This reflection comes from a developed case study in the penitentiary Central La Picota of Bogota, Colombia with a person who was condemned to deprivation of freedom in their prison yards, and supplies on research developments in the phenomenon of prison. It also ponders the influence education has on the formation of subjectivity and the essential and influential of the contexts in education. Shown as part of the causes of common crime has its birth in the lack of educational coverage and promotion opportunities by State. Finally, it addresses the theoretical conceptualization of the subjectivity from three authors to show that prison spaces determine a variant that has been poorly developed.
\end{abstract}

\section{Keywords}

crime; subjectivity; education; jail; resocialization

\section{Resumo}

O artigo é uma reflexão sobre a contradição do programa de ressocialização do Instituto Nacional Penitenciario y Carcelario (Inpec), nas prisões colombianas. Dita reflexão nasce de um estudo de caso desenvolvido na prisão central La Picota, da cidade de Bogotá, com uma pessoa condenada à privação da liberdade em um de seus pátios. 0 artigo se alimenta das pesquisas sobre 0 fenómeno carcerário. Também se reflete sobre a influência que a educação tem na formação da subjetividade, sobre o fundamental e a influência dos contextos no educativo. Se expõe como, parte das causas do crime comum tem seu nascimento na falta da cobertura educativa e promoção de oportunidades pelo Estado. Por último, se propõe uma conceptualização teórica da subjetividade a partir de três autores para mostrar que os espaços carcerários determina uma variante que tem sido poço desenvolvida.

\section{Palavras-chave}

delito; subjetividade; educação; cadeia; ressocialização 


\section{Introducción}

$\mathrm{A}$ ntes de iniciar, quisiera hacer algunas claridades de tipo metodológico acerca del trabajo investigativo que precede a este artículo.

La investigación se planteó en tres etapas: la primera fue de acercamiento al fenómeno de la cárcel, a partir de la lectura de artículos e informes que dieran una idea y guiaran en las concepciones y las categorías relevantes para comprender la situación actual de la cárcel en Colombia. Esta etapa bibliográfica consolidó la elección de las categorías de la investigación y puso pie en tierra para comprender el problema carcelario y poderlo ver desde un enfoque menos institucional. Trabajos internacionales ${ }^{1}$ y nacionales ${ }^{2}$ fueron dando cuenta de los elementos que constituyen el fenómeno carcelario.

Hablar de la cárcel significaba, después de estas lecturas, referirse a una cultura del control (Garland, 2001), tener en cuenta el enfoque preventivo o correctivo (Rivera, 2014), disociar el castigo de la justicia (Beccaria, 2014), encontrar validez en la defensa de los derechos humanos de los presos, ser consciente de la responsabilidad individual y estatal en los actos criminales, entender cómo los medios de comunicación, en algunas ocasiones, son modulados para pretender una visión respecto a un tipo de crimen, comprender los tipos de poderes que conviven en la cárcel y cómo se alternan y, definitivamente, desnaturalizar el concepto tan nombrado de resocialización.

Ya para el trabajo de campo, como segunda etapa, se planteó la elección de la técnica social y del método investigativo desde el mismo contexto de investigación. La plasticidad que exigió dicho contexto dejó como alternativa única la obtención de esta información, a partir de una serie de entrevistas que se realizaron dentro de la cárcel en el rol de visitante con una persona privada de su libertad que yo había conocido antes de estar en esta situación y que aceptó trabajar en este proyecto; me refiero a plasticidad porque pese a las gestiones institucionales no se me otorgó un permiso especial como investigador.

Mientras se realizaban las entrevistas también se obtuvieron datos desde la observación planteada por el enfoque etnográfico. La manera como se obtuvo

1 Algunos de ellos fueron: Baratta (1990), Beccaria (2014), Caballero (1986), Foucault (1998), García (2004), Garland (2001), Pegoraro (2011), Pérez (2000), Rivera (2010), Wacquant (2010), Zaffaroni (1998)

2 En este grupo están: Ariza e Iturralde (2011), Castaño (2005), Gaitán y Peláez (2000), Gallego y Posada (2013), Ordóñez (2004), Torres y Arias (2011). la información estuvo coincidencialmente acertada, pues el día sábado, cuando yo asistía, y en el que además los presos reciben visitas masculinas, estos tenían una disposición casi ansiosa al diálogo $\mathrm{y}$ al acercamiento, posibilidad que tal vez no se me hubiera abierto si mi asistencia fuera entre semana, donde las ocupaciones determinarían otra actitud. Estas entrevistas tomaron entre 15 y 16 meses, donde por lo menos una vez al mes se realizaba alguna.

Como el interés era no solo conocer la historia en la cárcel de la persona que entrevisté, sino tratar de comprender su subjetividad, en algunos momentos este objetivo se tornaba difuso, porque la vivencia subjetiva no constituye una relación directa con lo material; hay realidades espirituales, mentales y sensitivas que hacen compleja su captación e incluso pueden llenar de presuntos las observaciones investigativas. Por tanto, hallé consuelo de dicha comprensión en la expresión personal sobre cada acontecimiento que iba pasando en su vida, de tal forma que los sentimientos, los razonamientos, los gestos, las ideas y la interacción con los demás fueron la vía para complementar el entendimiento de lo que significa la encarcelación.

En la etapa final, que fue la de escritura analítica, el cruce de información desde lo bibliográfico y desde el trabajo de campo permitió llegar a conclusiones relevantes, algunas teóricas, como el hecho de que la teoría de lo subjetivo aún no explora lo suficiente este tipo de experiencias de vida, o también cómo los poderes que se articulan en la cárcel terminan siendo una perspectiva para comprender el sistema carcelario colombiano. Y algunas de tipo práctico, en términos de entender la relación de los presos entre ellos y con la guardia del Instituto Nacional Penitenciario y Carcelario, Inpec. Los deseos, códigos y formas de vida que se desarrollan en la cárcel en un contexto de hacinamiento, la violación permanente de los derechos humanos, la sobrepoblación carcelaria, la corrupción administrativa y la afirmación de un precario programa resocializador.

Quedó en mi cabeza esta última idea, de cómo en un escenario de este tipo puede un programa de resocialización funcionar y cómo este concibe el aspecto subjetivo, social y económico de los presos, con el entendido de que la resocialización es normativamente el fin de la pena y que valida la existencia de la institución carcelaria en Colombia. Todo esto se constituyó en el argumento principal para desarrollar la reflexión que se presenta a continuación. En resumen, utilicé las ganancias investigativas para ahondar sobre uno de los conceptos fundamentales del tema carcelario, a saber: la resocialización y el implícito educativo que contiene. 
Un último punto por resaltar, antes de entrar de lleno en el desarrollo de este artículo, es el hecho de que puede parecer un problema metodológico que de un estudio de caso se extrapolen conclusiones acerca del programa de resocialización carcelario colombiano, pero existen consideraciones por las que esta asociación puede darse sin incurrir en un error de procedimiento:

Media la relación relato/correlato, en la medida en que lo que cuenta un preso común, ${ }^{3}$ y que en efecto tiene una marca subjetiva que lo diferencia de los miles, obedece a un contexto, a una determinación espacial y a condiciones establecidas por el sistema carcelario en Colombia que tiene un carácter nacional. Los cuerpos de seguridad y control, su organización administrativa, los traslados de personal y de presos no están limitados por las consideraciones regionales $y$, dicho sea de paso, las denuncias de corrupción, limitación presupuestal, condiciones de infraestructura, afectaciones de los derechos humanos, entre otros, no tienen fronteras. Al estar las cárceles manejadas y administradas por una misma entidad en el orden nacional, las réplicas de su modus operandi difícilmente varían. Lo que sí haría la diferencia sería el número de personas al que llega el programa de resocialización en cada cárcel, pero como se desarrolla en este artículo, aun siendo totalmente aplicable, contiene problemas estructurales.

Por tanto, no interfieren perspectivas regionales ${ }^{4}$ que cambian la organización administrativa y operativa de la cárcel entre una ciudad y otra. En efecto existen diferencias entre cárceles en los criterios de máxima y mínima seguridad, de primera, segunda y tercera generación, pero en este momento la mayoría de establecimientos carcelarios presentan tales

3 Entendido como una de las miles de personas que ha cometido uno de los delitos que están categorizados e identificados en las mismas estadísticas del Inpec como de los principales actos objeto de condena y con una lista larga de sindicados intramurales. Los presos comunes se deben entender como aquellos que están detenidos en patios de reclusión sin comodidades o tratos especiales, también lo define el tipo de delito que cometió, el grado educativo con el que ingresa a la cárcel, su nivel socioeconómico y la edad. Quedan por fuera de este grupo los presos que cumplen casa por cárcel y los que por su condición socioeconómica a favor pueden arreglárselas para cumplir su condena en guarniciones militares o en patios con adecuaciones especiales. Es sobre estos presos comunes donde el programa de resocialización basa sus resultados de éxito y fracaso (Inpec, 2019a).

4 Según el mismo Inpec en su informe de enero de 2019 (2019a), esta entidad está a cargo de la mayoría de la población intramural en el país, con un 98,3 \%; los otros encargados, como los establecimientos de reclusión de orden municipal y establecimientos de la fuerza pública, representan el $1,2 \%$. similitudes ${ }^{5}$ que hacen que las medidas que allí se adelanten tiendan a ser homogéneos; la administración, en su gran mayoría, funciona con los mismos criterios, sobre todo en lo referente al programa de resocialización que se intenta aplicar sobre un índice nacional de hacinamiento de un 48,8 \% (Inpec, 2019a).

Entendiendo esto y sabiendo que esta reflexión se enfoca en el programa de resocialización como un intento unísono de educar en la cárcel, es válida la relación analítica entre lo particular y lo general. Porque precisamente el efecto de lo estructural recae sobre los individuos y este artículo reflexiona sobre ese aspecto, sobre el componente grueso que es el programa de resocialización en sí, que si bien afecta individualmente se plantea en términos generales. Por lo general, un caso no puede dar cuenta de un problema, pero acá dio lo necesario para sospechar e indagar sobre algo que institucionalmente no se plantea, y es la crítica a uno de los aspectos fundamentales que soportan la lógica carcelaria en la que suele confundirse aplicación con resocialización.

\section{Reflexión a partir del concepto de resocialización}

En un aparte, Foucault (1982), desde la óptica del lenguaje, se refiere a las unidades descriptivas que totalizan significados y a las que se les asocian atribuciones que parecen cristalizar universos sociales y darles una especie de armadura semántica e interpretativa que cimientan realidades discursivas, construidas e instituidas en la mezcla con los factores políticos, económicos y sociales.

Lo anterior puede en parte explicar cómo las instituciones necesariamente deben organizar y controlar los significados de los objetos conceptuales que las constituyen para poder mantenerse vigentes y legítimas, aun cuando pueda ser incongruente la significación y la descripción de la realidad que cada una de estas delimita.

En el caso de la educación como forma social instituida encargada de la transmisión de cierta información en contextos determinados, se debe entender que esa cristalización de los significados ha logrado un desarrollo social, cultural, ideológico,

5 En el informe estadístico del mes de febrero de 2019 realizado por el Inpec, se hace una clasificación del tipo de construcciones de cada una de las cárceles del país sobre las que esta institución ejerce dominio. Las construcciones de primera generación son las que primero se construyeron, por ende, las más antiguas y deterioradas que terminan siendo la mayoría (Inpec, 2019a). 
teórico y práctico tal, que le permite a cualquiera que quiera diseñar un proyecto educativo tener una serie de referentes para su estructuración. Esos referentes son una herramienta no solo para estructurar tal proyecto como institución, sino para moldear un tipo ideal de individuo.

Para este caso, es motivo de análisis y reflexión el proyecto que el Inpec, como organismo encargado de resocializar a los delincuentes, desarrolla dentro de las cárceles colombianas, que en la norma se basa en el trabajo y la educación como herramienta restaurativa. Y aunque el mismo Inpec acepte que este programa carece de la fuerza y el impacto deseados, ${ }^{6}$ tanto por las condiciones carcelarias de la población como por las poscarcelarias, esta reflexión gira en torno a la idea de que aun gozando de óptimas condiciones, el proyecto educativo como eje resocializador carece de la conciencia social suficiente para cumplir su tarea. No se obtienen los resultados esperados ni podrán obtenerse tal y como se plantea el programa.

En parte porque los reclusos son una población aislada, no solo desde el plano físico, siendo el foco de atención en términos de política pública escaso, por no decir nulo. Descriptivamente, la labor de la política criminal ${ }^{7}$ se centra en apresar y encarcelar, pero no existe una estrategia estatal clara hacia la atención a esta población. Todo esto lo refleja el panorama actual de las cárceles colombianas, ${ }^{8}$ que por sus características presenta grandes dificultades a la hora de querer aplicar principios educativos que intenten cambiar la forma como la persona, antes de entrar a la cárcel, es decir, en el momento que cometió el delito, percibía la realidad social. Por todo esto, el concepto resocialización es problemático, desde su cobertura y desde su contenido.

6 En su Plan de direccionamiento estratégico 2015-2018 (Inpec, 2018) se señalan las razones por las que las actividades del proceso de resocialización carecen de condiciones de efectividad y eficiencia.

7 El trabajo denominado Análisis de la situación carcelaria en Colombia: un enfoque cualitativo (Gaitán y Peláez, 2000), aunque publicado en el año 2000 sigue vigente, pues las condiciones que describe, principalmente la inexistencia de política criminal, el hacinamiento y la vulneración de los derechos humanos se encuentran en el mismo estado, esto ha sido remarcado en las posteriores pronunciaciones de la Corte Constitucional sobre el estado de cosas inconstitucional en las cárceles de Colombia mediante sentencias T-153 de 1998 y T388 de 2013 y reiterado en la Sentencia T-762 de 2015.

8 Entre lo descrito en el informe realizado por Elke Kooyman (2018), experta en detención del CICR, se relacionan varios aspectos por los que se hace evidente la crisis del sistema carcelario en Colombia; tasas de hacinamiento que superan el $365 \%$, calidad deficiente en la atención primaria y acceso a servicios de salud, falta de espacios de esparcimiento, y resocialización y obsolescencia de la infraestructura.
La cárcel, más que una solución, resulta un problema; en ella se condensan las ideas de discriminación, castigo, delito y crimen, y eso tiene repercusiones negativas para la mayoría de las personas que la viven. Sus alcances llegan solo hasta el punto donde el delincuente es apresado; tiene una funcionalidad social tranquilizadora, más que estar dirigida a resocializar al delincuente (un mito), está orientada a intimidar al ciudadano común con el mensaje de que si se indisciplina será sancionado (Tobón, 2014). Y lo que ocurre dentro de ellas ${ }^{9}$ pasa al olvido fácilmente.

La cárcel, entre todas las demás significaciones, es privación de la libertad. Pero ¿libertad en qué sentido?, pues interrumpe lo que un ciudadano hace cotidianamente, cualquiera que sea su oficio, su ocupación. En Colombia, esa posibilidad de hacer es un derecho, el cual se pierde toda vez que se es condenado por un delito, o antes, según la detención preventiva de la libertad. En la cárcel se castiga a partir de la supresión de tal libertad; sin embargo, y según lo dice la norma, ${ }^{10}$ su principal objetivo no es solo este, sino también resocializar a partir de la educación como herramienta y como contenido. Esta educación significa principalmente inculcar en el individuo los valores ${ }^{11}$ que por su demostrada situación ha perdido, o nunca tuvo. Esta acción resocializadora supone que la dinámica social fuera de la cárcel es equilibrada y que el delincuente la vulnera. Pero, paradójicamente, las condiciones sociales, económicas y culturales de la sociedad colombiana no están en perfecto equilibrio, y tal vez nunca lo estén, tal vez no exista tal; por eso, desde el principio, la resocialización es una contradicción. Tanto por la forma como se concibe la educación en el programa

9 Por ejemplo, el periódico El Tiempo (Serralde, 2018) publicó, basado en un informe de la Contraloría General de la Nación, la nota de prensa "Los ingredientes que cocinan la crisis carcelaria desde hace 20 años". Según la Contraloría, en el año 2018, se evidencia una ausencia de resocialización y un denominado populismo punitivo en el sistema carcelario que lo hace ineficiente.

10 La Ley 65 de 1993 reza en su artículo 9: "Funciones y finalidad de la pena y de las medidas de seguridad. La pena tiene función protectora y preventiva, pero su fin fundamental es la resocialización. Las medidas de seguridad persiguen fines de curación, tutela y rehabilitación".

11 En el entendido de que "la educación transforma y potencia al hombre natural para hacer emerger un hombre distinto. Lo hace sabio, inteligente, conocedor, industrioso, prudente, independiente, seguro, indagador, amoroso, disciplinado, honesto, alegre, ético, sabiendo la diferencia entre el bien y el mal, proclive al bien, a la ciencia y al conocimiento, así entenderá la justicia y la equidad y se acercará al bien y se alegrará de lo que es virtuoso, y físicamente fuerte para soportar las inclemencias del tiempo y las exigencias del trabajo" (León, 2007, p. 600). 
resocializador, como por el olvido intencional de lo que significa el mundo del delito y, también, por el desconocimiento de las condiciones propias de la dinámica carcelaria. Pero hay que ser más claro.

\section{Cúmulo de contradicciones}

\section{Contradicción de equilibrio}

Tiene que ver con la idea de que los individuos que están en las cárceles han alterado el equilibrio de la sociedad. Pero no siempre se castiga el fomento del desequilibrio. Es evidente que los grandes problemas ambientales, sociales y económicos actuales son el resultado de procesos sociales que se dan desde la concepción del imaginario del mundo, propiciada por los gobiernos y los sistemas económicos frente a los que no hay una denominación criminal, no se determinan como acciones desequilibradas sancionables. Es deducible que la cárcel no es el lugar exclusivo de los desequilibrados sociales; en efecto, el orden económico y social mundial puede alterarse por el fenómeno del narcotráfico, o la estabilidad psicológica de una población puede alterarse por la violación sexual hacia alguno de sus habitantes, y por eso como recurso práctico se acude a la cárcel, pero el equilibrio del mundo, como lugar habitado por nuestra especie, está alterado más por las formas de existencia política y económica que promueven conductas orientadas a ver el éxito y el fracaso económico, y su derivado estético como puntos de referencia que llevan al exterminio.

A algunos desequilibrios se les permite su expansión sin una establecida sanción penal, como la gestión de las guerras en lo geopolítico, o el daño que produce una transacción bursátil a miles de agricultores ${ }^{12} \mathrm{y}$ consumidores, acciones para las que no hay más que descontentos, pero que no se configuran como delito y pueden en efecto ser más devastadoras que el hurto de un teléfono móvil. De ahí que el recurso carcelario se conciba para algunos $\operatorname{críticos}^{13}$ como una extensión del poder jurídico a las órdenes del poder económico sobre personas indefensibles,

12 Martín Caparrós, en su libro El hambre (2014), explica la forma como la especulación ejercida por algunos corredores de bolsa en el instante de una transacción repercute negativamente al otro lado del planeta en miles de agricultores de maíz, soya o frijol.

13 Entre estos, David Garland, en La cultura del control (2001), hace un análisis en el contexto norteamericano de la denominada lucha contra la delincuencia, donde argumenta que la política criminal más que ser el intento por combatir el delito, resulta un instrumento para ejercer la discriminación racial y económica que deja a los encarcelados en condiciones de desigualdad jurídica respecto a otros grupos poblacionales. con la intención de evadir las responsabilidades sociales hacia los ciudadanos. Aunque no hay que polarizarlo sentenciando que en la cárcel residen solamente los inocentes que no tienen poder o a los que se les ha inculpado en desventaja. En efecto, la historia demuestra que hay acciones siniestras en las que todas las sociedades coinciden en la categorización de un acto como delito. Como el asesinato, las violaciones o el secuestro. Sin embargo, en términos de delitos como el hurto, que tiene miles de condenados ${ }^{14} \mathrm{y}$ que, en sus motivos, lo que quiere el que lo ejecuta es dinero, como valor de intercambio supremo, no obedece solamente a una manía o desviación psicológica, más bien, puede obedecer a una reacción individual producto de la desigualdad que ese desequilibrio económico impone.

Si se quisieran entender y tratar de parte del gobierno las causas sociales, económicas y culturales ${ }^{15}$ del delito, tal vez no hablaríamos de hacinamiento en las cárceles, en cuanto esta comprensión voluntaria plantearía soluciones preventivas y sensatas sobre cada tipo de delito, donde se asumirían responsabilidades de parte de los actores implicados, tanto el individuo como ciudadano, como el gobierno encarnado en las instituciones económicas, sociales y políticas.

\section{Contradicción educativa}

La educación como práctica y concepto ha sido ya bastante conceptualizada y discutida; sin embargo, hay adjetivos que, aún criticados, son coincidentes. En su seno, la educación es una oportunidad para expandirse, aprender, aprehender, conocer, reconocer; es una apertura a comprensiones nuevas y a posibilidades de pensamiento y práctica cultural, es lo que la cultura quiere transmitirle al individuo, pero también la invitación a que este individuo se relance, invente, se distancie con criterio. Pero, no solo está entendida como eso, también está consagrada en

14 En el Tablero de control de delitos del portal virtual del Inpec, se realiza una descripción de los delitos con mayor incidencia a nivel nacional. Puntea el hurto, el homicidio, el tráfico, fabricación o porte de estupefacientes, concierto para delinquir y fabricación, tráfico y porte de armas de fuego. Recuperado de http://www.inpec.gov.co/estadisticas-/tableros-estadisticos

15 Erich Fromm, en su obra Psicoanálisis de la sociedad contemporánea (2011), plantea el cuestionamiento a la sociedad global de si sus parámetros de conducta, la relación que establece con sus individuos y las formas de producción, no ha derivado en un ambiente nocivo que trae consecuencias psicológicas negativas para sus mismos habitantes, y que los expone a imaginarios colectivos que pueden ser contraproducentes para su bienestar emocional, los convence, por ejemplo, de que el éxito, el prestigio y el reconocimiento son fines a conseguir a través de cualquier medio, por violento y transgresor que sea. 
la ley colombiana como un derecho constitucional y en este caso es la base del proceso resocializador en las cárceles de Colombia. Aquí se establece esta contradicción; para algunos jóvenes, delincuentes comunes, no ha existido en sus vidas la posibilidad de ejercer este derecho o no existe en su proyecto vital una orientación a lo educativo institucional como forma de vida. Estas carencias pueden ser causantes de la elección de caminos ilegales en su vida; en el contexto inmediato, el joven recibe informaciones donde el camino ilícito se muestra como el proceso educativo inmediato y efectivo, en cuanto posibilidades de prestigio, poder y dinero. La valoración que compone a lo criminal resulta más atractiva por su inmediatez y efectividad, pues guarda equivalencia con el éxito. Hay que entender que los criminales en gran parte se construyen y el contexto contribuye a esa construcción. Hay una educación que desborda a la otra y la aventaja.

Y luego, en la cárcel, se les intenta dar algo que jamás han tenido, dentro de un contexto represivo y violento, que no garantiza en nada el aprendizaje con fundamento resocializador. $Y$ respecto al contenido, es más parecido a algo que se puede llamar alfabetizador, y aunque en algunas cárceles se les intente educar para el trabajo, por ejemplo, en labores de carpintería, mecánica, artesanado; parecen insuficientes cuando se analiza la oportunidad laboral que tendrían en la calle, sabiendo que en libertad no podrían desempeñar con facilidad la labor aprendida y que, tal vez, a través de su actividad delictiva obtienen mejores y más rápidos resultados. Es una educación que no contribuye a la superación de las condiciones materiales, espirituales e intelectuales existentes; la educación en la cárcel no está alineada al movimiento social y económico de la sociedad colombiana ni a la comprensión del delito como fenómeno social, es una educación placebo, cumple más con la función de matar el tiempo que como el inicio de un proyecto de vida redireccionado. Venidos de un mundo precario, se les intenta dar una educación precaria, en un contexto precario para que salgan a un mundo lleno de incertidumbres. Concebida así, la educación que se imparte en la cárcel es un retroceso en el movimiento del mundo actual; se busca combatir un problema estructural con una medida tópica ineficaz.

\section{Contradicción de significado}

Resocialización, en su sentido significativo, es llevar, devolver a alguien a un estado en el que se encontraba, al estatus socializado. El sistema penal presume que lo suficiente para estar socializado es no cometer crímenes, equivale a no actuar ilegalmente, supone que el individuo socializado tiene incorporado en sus prácticas cotidianas comportamientos legales, a pesar de las situaciones por las que pase, debe estar acorde con las leyes. Luego, si ejecuta un acto ilegal y es llevado a la cárcel, a través del proceso resocializador, se le dota de las herramientas ciudadanas necesarias para que en un futuro no viole la ley, todo esto entendiendo que el único responsable de la comisión del delito, de los motivos que lo llevaron a cometerlo, es el individuo.

El Estado en nombre del liberalismo da la espalda y olvida que la comisión de delitos forma parte de un sistema; sus causas (y ya se demostró hace tiempo) ${ }^{16}$ no son genéticas, tienen que ver con una situación social, moral, cultural y de distribución de la economía en cada sociedad, complementada con los imaginarios valorativos de riqueza, poder, ambición y justicia. Una persona socializada puede estar tan afectada emocionalmente como la sociedad que le suministra esos valores que la guían en su actuar. El hecho de que la significación de un concepto esté dada desde los entes de control o las instituciones no significa que contengan lo necesario para vivir mejor en sociedad. Los Estados suelen equivocarse demasiado, las formas legales de significación también; ya han pasado por nuestros ojos demasiadas categorizaciones sobre lo correcto, lo bueno y lo sano que han demostrado no estar a la altura de las necesidades sociales: la crisis de corrupción vigente, las formas políticas de llegar al poder, la desfachatez con que se reparten los dineros públicos, todo esto es muestra de que la denominación de algo no significa que sea ese algo.

Socializar y resocializar no son conceptos que deban ser utilizados en un contexto como el carcelario, pues, solo representan la puesta en escena de una forma de llamar algo que no es; ambos carecen de enlace práctico y empírico, solo se mencionan para publicitar una función que no se realiza. La cárcel en realidad no es útil para resocializar, es un escenario volátil en su sentido y utilidad. En ocasiones, sirve para asustar a los de afuera, para controlar a otros, para reprimir, para vetar, para aislar. Su significación varía de acuerdo con las necesidades de los entes que la controlan, lo que la hace una herramienta política, no es lo que dicen de ella, más bien es lo que no dicen.

16 En el libro Delitos de los Estados, de los mercados y daño social, editado por Iñaki Rivera Beiras (2010), se describen en detalle las otras causas sociales asociadas al delito desde una perspectiva crítica. Antaño se creía que el criminal nacía determinado hacia la maldad, ahora se ha logrado demostrar, gracias a trabajos como este, que las causas del delito en la sociedad obedecen a factores sociales, económicos y de imaginarios colectivos construidos. 


\section{Contradicción por ausencia de reconocimiento}

Esta tiene que ver directamente con la anterior; como el que controla el delito es el Estado, este debe reconocer que la comisión de este es un fenómeno que no es asocial, ${ }^{17}$ sino que forma parte de la constitución de las relaciones sociales. El delito debe ser tratado con absoluta prudencia, no debe verse tal como se ha representado hasta ahora (el gato detrás del ratón), sino como un fenómeno que merece estudio, aceptación de responsabilidades y decantamiento de soluciones. Encarcelar no significa combatir el delito, debe reconocerse que la frase legal de que "el fin de la pena es la resocialización" queda corta y es un lugar común frente a las necesidades sociales de tratamiento del delito. El delito evoluciona como evolucionan las sociedades, por tanto, la ley y el Estado no pueden anquilosarse y pensar que en el espectáculo televisivo está el tratamiento criminal y la función social.

Países donde el nivel de los delitos es bajo ${ }^{18}$ demuestran que estos pueden entenderse como no correspondientes a un tema evolutivo genético de sus habitantes; los bajos índices obedecen a que se han instaurado medidas especiales para, primero, entender y, luego, tomar acciones; se ha privilegiado la prevención del delito con medidas alternativas de derecho y de atención hacia la población y no la corrección y la cacería al estilo cinematográfico. El delito tiene en gran parte una causa social, con atisbos culturales que se han ido construyendo a lo largo de la historia en cada sociedad.

17 Pegoraro (2011) desarrolla la idea de que el delito ha sido parte fundamental y constitutiva de la construcción de las sociedades, y que aunque se ha intentado ver como un fenómeno de maldad y de desviación, ha figurado en la historia de la humanidad, siempre actuando con una moralidad alterna, disyuntiva. El delito se publicita como algo anormal, pero en realidad está adherido a la construcción de la sociedad de forma institucional y penetrante. Por tanto, la idea de mostrarlo por parte de los gobiernos como algo atípico no es congruente con la historia simbiótica del delito en la sociedad, ha sido una tergiversación de la realidad histórica.

18 The Legatum Institute (2018) publica un informe anual sobre los factores que, según su criterio, consolidan una estabilidad social, entre ellos se enumeran: educación, salud, medio ambiente, desarrollo económico, y seguridad y protección. En las diez primeras posiciones se encuentran países de la zona europea. Colombia, aunque en la clasificación general se encuentra en el puesto 66, en seguridad y protección - que se asocia con los aspectos de comisión de delitos-, se ubica en el puesto 142 de 149 .

\section{Resocialización como educación y la subjetividad íntima no manifestada}

Tal y como es concebida por algunos autores, ${ }^{19}$ la subjetividad se acerca a la afirmación de la libertad (Touraine, 2000), al proceso de trascendencia (Zemelman, 2007), a la aplicación de resistencias (Giddens, 2011); es la intención de manifestación individual que se constituye en rompimiento de lo esquemático. Y lo subjetivo se alinea a los valores que la educación intenta estimular ${ }^{20}$ en cuanto proceso de adquisición de significados, de construcción de criterios propios, de obtención de comprensiones. Sin embargo, en la cárcel colombiana, la educación es más un proceso de adoctrinamiento y de conducción ${ }^{21}$ que cree que el preso logrará resocializarse a través de la inyección de información que le dará lo necesario para posteriormente no cometer delitos.

Su objetivo educativo es alinear al individuo, modificarle sus conductas delictivas desde ciertas actividades resocializadoras. Por cierto, estas carecen de perspectiva tanto crítica como vocacional; se enseñan oficios artesanales y estudios básicos académicos que no garantizan que ese proyecto resocializador sea eficaz, sumado a que los niveles de información y competencia profesional impartidos dejan a estas personas en evidente desventaja. ${ }^{22}$ Para los que pue-

19 Para el análisis desarrollado en este artículo se tomaron como referencia tres obras correspondientes a tres autores: Hugo Zemelman y su libro El ángel de la historia (2007); Anthony Giddens, y La constitución de la sociedad (2011), y Alain Touraine, y su texto ¿Podremos vivir juntos? (2000).

20 Aunque este acto educativo sea paradójico, en concordancia con lo que León (2007) menciona, "educar es formar sujetos y no objetos, tiene el propósito de completar la condición humana del hombre, no tal y como la naturaleza la ha iniciado, la ha dado a luz; sino como la cultura desea que sea. En este sentido la cultura y la educación, su gran aliada son tremendamente conservadoras. Es una manera, es un esfuerzo de adaptar el hombre al medio. Porque la educación es construcción de algo que la cultura considera que es digno de mantener" (p. 598).

21 Entendiendo, eso sí, que hay mucho de paradójico en los procesos de enseñanza, pues aun promoviendo lo crítico y lo deliberativo se deben asumir algunas verdades y realidades sin tanto análisis crítico, pues de otra manera cada individuo debería recapitular todo el conocimiento humano y someterlo a duda.

22 Torres y Arias (2011) describen los evidentes problemas que el programa educativo PASO (que se implementa en las cárceles colombianas para cumplir con el objetivo resocializador) 
den acceder a una actividad educativa o laboral en la cárcel, esta se constituye más en una forma de ocupar el tiempo que la vinculación a un proyecto que les pueda dar despliegue profesional, laboral o personal.

Pero no solo lo educativo constituye al programa, ya es sabido que lo contextual - como el entorno en el que el individuo vive e interactúa y en el que interioriza significados- es determinante. Recibir cierta información en un ámbito social específico influye en la adquisición del conocimiento. El escenario en el que los presos, dentro de un criterio no formal, reciben información y que deriva en lo que denomino subjetividad íntima no manifestada es atípico. De allí que la concepción de que la subjetividad es siempre acción, manifestación, rompimiento, es más un deseo teórico, pues allí, está limitada.

Tanto en el aspecto institucional como en el de normalidad alterna, ${ }^{23}$ el preso común sufre de una constricción total, lo único que le queda es esta subjetividad intima no manifestada, que es un mantenimiento mental y espiritual de su vida y su existencia, podría compararse con la retrospección, la inmersión, allí resulta en quietud y limitación.

Así resiste, se erige, existe, se adapta. En el contexto carcelario los presos están en la tensión permanente de adaptarse a las órdenes impartidas por los entes reguladores existentes; por un lado, el Inpec, con el monopolio de la fuerza normativa y física atribuido por la legalidad y la legitimidad, y por el otro, el orden establecido por la cultura delictiva, ilegal y también legítima. Ante estos dos órdenes, el preso común debe establecer una estrategia de adaptación para sobrevivir, que por lo general dista de la resistencia expresiva, más bien utiliza una forma pasiva y sumisa, pero que lleva implícita una finalidad, que es la de poder transcurrir el tiempo de condena sin daños considerables a su humanidad.

Con esta forma subjetiva se pone en evidencia la relación entre mente y cuerpo, relación bastante interesante, porque deja una inquietud sobre la

ha tenido en su desarrollo y aplicación. Varios factores fortalecen este argumento: hacinamiento, precario presupuesto, falta de adecuaciones físicas, y el mecanismo de redención de la pena, que hace que los presos se inscriban a estos programas más para rebajar días en prisión que con una actitud resocializadora.

23 Con normalidad alterna me refiero a la estructura normativa que los mismos presos han construido, hay formas de comportamiento, economías y reglas que son organizadas, propuestas y supervisadas por ellos, y que tienen una base sancionatoria violenta. importancia del cuerpo como contacto con el mundo objetivo, pero en permanente relación con el mundo subjetivo. El cuerpo cumple un papel de actor, en donde sus actos no siempre logran (para aquellos que tenemos la intención investigativa) acercarnos al conocimiento del interior, o son lo que creemos que lo moviliza, entendiendo que siempre lo precede un pensamiento cargado de intencionalidad..$^{24}$ Las manifestaciones corporales obedecen al poder que se tenga en el mundo social para hacerlas posibles, pero, cuando no hay poder no quiere decir que esté anulado el deseo de liberarse: es, en tanto, según sus posibilidades. Dadas por un contexto entendido como el escenario de lo posible, este educa en ciertos contenidos sin buscarlo, las informaciones son boomerangs que van y vienen, no hay un control curricular, pero tiene una fuerza pedagógica en los individuos que lo experimentan

La subjetividad que se manifiesta corporalmente solo es posible en una relación directa con la libertad, que sería el escenario de despliegue. Existe, entonces, un límite teórico evidente cuando se hace referencia al escenario carcelario, pues allí la manifestación de la subjetividad es posible, no solo en cuanto voluntad, sino condicionadamente; es casi un privilegio. Por otro lado, está la idea de que la subjetividad no solo se manifiesta en la acción, digamos en actos corporales, sino también en la omisión de conductas, en los pensamientos. Esto plantearía dos facetas de la subjetividad, una mental y otra corporal, pero no necesariamente están sincronizadas. Puede en lo corporal no existir una manifestación subjetiva mental y su contrario, en la manifestación mental puede no existir la corporal.

La libertad corporal podría ser complementaria a la mental, pero en ciertas condiciones de contexto no se manifiesta. Parece que la subjetividad manifiesta en lo corporal es más un performance, una necesidad de expresión que quiere decir algo, no solo como manifestación subjetiva sino como una manifestación subjetiva en lo objetivo. Mientras que la subjetividad mental pasa a un punto en donde la manifestación corporal se nulifica, su ámbito se restringe al sujeto por condiciones de contexto en efecto. Luego, la parte de la libertad en el no acto aparece como manifesta-

24 A estas alturas de la historia de la ciencia social ya es común hablar de los actos y las intencionalidades, camino marcado sobre todo por la sociología comprensiva de la que Max Weber, en su obra Ensayos sobre metodología sociológica (2014), había realizado un análisis. Pero viene al caso el hecho de que el acto que intento mostrar no tiene todas las garantías de despliegue y por tanto su comprensión es un poco más compleja. 
ción que no se despliega; la subjetividad no necesariamente se manifiesta en el movimiento, también existe en la no manifestación, su expresión depende de unas condiciones, pero no quiere decir que donde no hay expresión no hay motivos ni necesidad de ser liberación, solo es una adaptación que se renombra en otra forma de ser, que es otra manera de expresión. Es una subjetividad mental que resguarda el sufrimiento corporal.

Entonces, lo real no solo está en el consenso social, por supuesto, también en el pensamiento, que no todas las veces se expresa. La noción de la subjetividad diferencia individuos y sujetos; individuo básicamente es aquel que obedece y sujeto el que rompe. Pero con la subjetividad íntima no manifestada se demuestra que un sujeto que resiste puede parecer individuo, si el grado de constricción del contexto se lo exige. La subjetividad se evidencia de una manera particular en relación con el contexto en el que participe. Aunque el proyecto educativo en la cárcel se orienta hacia una fallida resocialización, resulta que lo que enseña la fuerza obligatoria del ambiente no es motivo de registro ni tomado en cuenta como un aprendizaje. La cárcel enseña, no lo que desea, sino a partir de sus prohibiciones. Y tal vez ese sea el objetivo de la cárcel, aunque utilice el eufemismo resocialización.

\section{El aporte de la educación contextual no formal a la subjetividad}

Si se evalúa la condición de ser sujeto por el grado de conciencia y voluntad política que propone la teoría del sujeto en manos de Zemelman (2007) y Touraine (2000), difícilmente podemos encuadrar allí al sujeto carcelario. Las intenciones del preso común no se dirigen a modificar su orden social, se dirigen a su supervivencia. Este busca transformar su situación desde la obligatoriedad del escenario en el que fue depositado, su voluntad nace de allí, su conciencia se establece desde este criterio. El sistema carcelario ve al preso como:

[...] un sujeto despojado, puro, con potencialidad maleable y esculpible por el sujeto enseñante. Ese sujeto en estado de pura competencia no es, por supuesto, el otro, sino el continente vacío educable de pies a cabeza, ciento por ciento. Este sujeto no es el de la interacción en una comunidad de lenguaje, mundo y pensamiento. No es el integrante de mi forma de vida y cultura, sino un sujeto abstracto, separado del contexto y objetivable por una mirada representacional y distanciadora. (Marín, 2007, p. 43)
Esta concepción del sujeto es de aquel que se deja modificar voluntariamente, sin atisbos de crítica, sin formas de expresión. No importa aquí su historia ni su momento vital, es exclusivamente a él al que se le responsabiliza por su falla, mientras que el Estado toma distancia de esa responsabilidad y concibe al preso como un transgresor patológico. Sin embargo, este sujeto adopta la posición maleable como una estrategia de permanencia y de lucha, el sujeto en la cárcel aguanta estas jornadas resocializadoras, cuando tiene acceso, solo con la idea de darle una distracción a su encierro, pero no con una actitud transformadora conjunta (institución/sujeto).

Cada preso construye la resocialización para sí mismo, desde su voluntad y su experiencia y no desde la propuesta institucional. El modelo pedagógico carcelario es un acto protocolario, no es el inicio ni el fin de la transformación personal, todo nace para el sujeto desde el propio choque con la realidad, desde su propia reflexión silenciada. Su manifestación, su acción, es un acto de postergamiento, de ulterior realidad.

El contexto en términos educativos y resocializadores es determinante. Para lograr transformación social positiva se necesitan herramientas pedagógicas que superen la saturación violenta del ambiente carcelario, pues este al fin y al cabo le gana la partida al programa institucional. Por bien o mal que se aplique, este modelo falla, pues no solo debe enfrentar el encierro como castigo, sino la fuerza social ambiental que produce el hacinamiento, la contravoluntad del aprendizaje de los individuos que ingresan a las cárceles y que se reafirma en la no obligatoriedad del programa resocializador, y el mismo ambiente carcelario que se ha construido por décadas y que piensa y actúa desde lo alterno ilegal, desde la trampa, desde el agite.

\section{Conclusión}

En definitiva, lo paradójico institucional se expresa en este modelo resocializador. Se concibe allí la educación como forma de transmitir unos valores sociales catalogados como necesarios, pero que en consonancia con los tiempos modernos están en crisis, aun cuando se pudieran transmitir eficazmente.

¿Qué es la educación?, si por más contenido no hay posibilidad de despliegue, de desarrollo, crítica, nuevas formas y maneras; así, no hay resocialización posible. El tipo de educación que posibilita el Inpec no es garante; este modelo educativo es corto, obsoleto y olvidadizo de la realidad social, en un contexto 
adverso a lo que significa la libertad, libertad que, erróneamente, se asocia con educación y formación de subjetividad. Este programa es simplemente una forma de confundir la responsabilidad que el Estado tiene de promover un ambiente sano y seguro para sus habitantes.

Teóricamente puede concluirse que no solo en la expresión corporal puede esperarse encontrar al sujeto, y ni siquiera en el lenguaje, los sujetos aprendemos, nos mimetizamos, nos escondemos, nos descubrimos, dependiendo de nuestras circunstancias y condiciones; estas últimas son dadas por el conjunto de la sociedad, que en general nos encubre con rutinas administradas formalmente. Y aunque no podamos modificarlas a nuestro antojo, le hallamos alternativa a esta imposibilidad, y ese es el recurso, a este acudimos, es nuestra compañía permanente.

No podemos seguir pensando que una acción social es menos leve que otra, no podemos exigirle al que se roba un teléfono, una billetera, una bicicleta, que no lo haga, si antes no se le dieron las garantías para que se desarrollara. La justicia no puede centrarse en señalar y castigar este tipo de actos, sabiendo que lo hace dentro de un contexto político económico que posibilita injusticia e inequidad, y que utiliza como herramienta el cinismo mediático. La corrupción, la política hostil, la exuberancia hedonista y la ambición sin restricción también nos perjudican como país, como conjunto.

La fuerza interior del sujeto debe poder manifestarse de una forma más libre, que permita el desarrollo de la sociedad en otro sentido, no visionado, no planeado, pero abarcante en términos de posibilidades no conocidas y con ansias de ser construidas con la imaginación. El control, las normas y las reglas no pueden ser la fórmula básica para la construcción de las relaciones sociales, se deben crear otras formas de convivencia sin que sean necesariamente obligantes, que posibiliten lo que no ha sido permitido hasta este momento. Y eso que no ha sido permitido no es más que la oportunidad para que todos los sujetos se expresen, es necesario un contexto más libre para esa expresión. Ese contexto se construye y se aprende a través del acto educativo, podemos asociarnos para llenarlo de criterio y de fundamento. Ese criterio no puede remitirse a una forma conductual que ponga términos a esas expresiones, pues esto sería reversar la potencia interior del sujeto. Las personas encarceladas son potencialidades mal dirigidas, o apagadas. La sociedad no puede permitirse, si quiere crecimiento, evolución, desmembrar el poder creativo, científico y emotivo que los sujetos pueden lograr. Lo que sí debe hacer es promover esas potencialidades a través de una educación específica. Antes de resocializar, debemos socializarnos.

La cárcel y su forma de remediar el delito promoviendo la transformación personal a través del trabajo y la educación básica está encadenada a un contexto violento, desaforado y corrupto. La cárcel educa desde su forma de ser, peligrosa y constrictiva, educa para la permanencia del individuo en este lugar y tal vez para la vida, pero esta educación no es compatible con el deseo resocializador institucional. El modelo resocializador necesita sensatez y voluntad. La importancia educativa que se le da debe ser alcanzada desde la articulación de los enfoques educativos. No debe crear un espejismo, dándole la espalda a las cualidades que el campo pedagógico y educativo contiene. Debe adaptar las comprensiones sobre los procesos educativos, en sus características y métodos. Debe crear un método que transforme. Si no, puede llamar a la resocialización, liberándose de la tensión que le exige la aplicación de los derechos humanos y en aras de la sensatez, de otra manera.

El hombre no puede desprenderse fácilmente de los significados y sentidos que su entorno social le da a la vida. El individuo parece encerrado en la semantización que su sociedad hace del mundo. Librarse de ese encierro implica compensar ese exceso de atributos lingüísticos con un pensamiento autónomo, que precisamente, significa tomar parte de la historia de la humanidad, de la sociedad, de lo global, y pasarlo por el filtro personal, esa parece ser la verdadera libertad que permitiría vivir más adecuadamente y a esto solo se puede llegar a través de la educación dentro de un contexto pertinente.

El desarrollo del modelo educativo del Inpec es el resultado de una forma de concebir su objeto de intervención, concepción que se instauró en la sociedad colombiana desde la mescolanza de los factores que construyen sociedad e institucionalidad en su conjunto. La cárcel colombiana no es más que el reflejo de la misma sociedad colombiana, y si queremos cambiar el modelo, debemos cambiar varias cosas; no solo la percepción que se tiene de la delincuencia, también cómo nos educamos, cómo entendemos los espacios educativos, lo formal, informal, contextual e institucional de la educación. Cómo tratamos a nuestros presos es el resultado de la carencia educativa que tenemos como país, como sociedad. Parece que la educación, como forma de transmisión y de entendimiento, ha sido monopolizada por lo político corrupto y económico indiferente. El cambio debe darse desde la ampliación de un contenido educativo 
que no solo nos prepare para profesionalizarnos o prepararnos para una actividad económica que nos dé sustento, también debe incluir fuertemente el aspecto humano y social, y aunque esto puede no dar garantía, porque la volatilidad humana es impredecible, por lo menos puede intentar hacer desde otro enfoque que muestre un avance en el entendimiento de este tipo de fenómenos.

\section{Referencias}

Ariza, L. e Iturralde, M. (2011). Los Muros de la Infamia, prisiones en Colombia y en América Latina. Bogotá: Uniandes.

Baratta, A. (1990). Resocialización o control social. Lima: Comisión Andina de Juristas \& Comisión Episcopal de Acción Social.

Beccaria, C. (2014). De los delitos y las penas. Medellín: Nuevo Foro.

Caballero, J. (1986). El mundo de los presos. Madrid: Alianza.

Caparrós, M. (2017). El hambre. Bogotá: Planeta.

Castaño, O. (2005). Cementerio de libertades. Medellín: Prográficas y Cía. Ltda.

Congreso de Colombia (1993). Ley 65 de 1993. Código Penitenciario y Carcelario. Recuperado de http:// www.secretariasenado.gov.co/senado/basedoc/ ley_0065_1993.html

Foucault, M. (1982). Las palabras y las cosas. México: Siglo XXI.

Foucault, M. (1998). Vigilar y castigar. Nacimiento de la prisión. México: Siglo XXI.

Fromm, E. (2011). Psicoanálisis de la sociedad contemporánea: hacia una sociedad sana. México: Fondo de Cultura Económica.

Gaitán, O.y Peláez, M. (2000). Análisis de la situación carcelaria en Colombia: un enfoque cualitativo: siete estudios de caso. Bogotá: Uniandes.

Gallego, E. y Posada, J. (2013). Delito y tratamiento penitenciario en el contexto de los derechos humanos. Medellín: Unaula.

García, S. (2004). Crimen y prisión en el nuevo milenio. Boletín Mexicano de Derecho Comparado, XXXVII(110), 547-595.

Garland, D. (2001). La cultura del control. Crimen y orden social en la sociedad contemporánea. Barcelona: Gedisa.
Giddens, A. (2011). La constitución de la sociedad. Bases para la teoría de la estructuración. Buenos Aires: Amorrortu.

Instituto Nacional Penitenciario y Carcelario (Inpec). (2018). Plan de direccionamiento estratégico 20152018. Bogotá. Recuperado de https://bit.ly/2Uxyazh

Instituto Nacional Penitenciario y Carcelario (Inpec). (2019a). Incidencias delito nacional. Bogotá. Recuperado de http://200.91.226.18:8080/jasperserverpro/dashboard/viewer.html?\&j_username=inpec user\&j_password=inpec\#/public/Delitos/Dashboards/ Delitos_Nacional

Instituto Nacional Penitenciario y Carcelario (Inpec). (2019b). Informe estadístico No. 2. Bogotá. Recuperado de https://bit.ly/2QZSGpZ

Kooyman, E. (2018). Cárceles en Colombia: una situación insostenible. Bogotá: CICR. Recuperado de https://www.icrc.org/es/document/ carceles-en-colombia-una-situacion-insostenible

León, A. (2007). Qué es la educación. Revista Educere, 11(39), 595-604. Recuperado de http://www.redalyc. org/articulo.oa?id=35603903

Marín, A. (2007). La noción de paradigma. Revista Signo y Pensamiento, (50), 34-45. Recuperado de https://www. redalyc.org/articulo.oa?id=86005004

Ordóñez, J. (2004). Rehabilitación y resocialización desde la justicia restaurativa. Cali: Universidad Javeriana.

Pegoraro, J. (2011). El lazo social del delito económico: un enfoque sociológico del orden social. Delito $y$ Sociedad, Revista de Ciencias Sociales, (31), 7-8. Recuperado de https://dialnet.unirioja.es/servlet/ articulo?codigo $=4702767$

Pérez, J. (2000). La construcción social de la realidad carcelaria. Lima: Pontificia Universidad Católica del Perú.

Rivera, B. (ed.). (2014). Delitos de los Estados, de los mercados y daño social. Debates en criminología crítica y sociología jurídico penal. Barcelona: Anthropos.

Rivera, I. (2010). Política criminal y sistema penal, viejas y nuevas racionalidades punitivas. Madrid: Taurus.

Serralde, D. (29 de octubre de 2018). Los ingredientes que cocinan la crisis carcelaria desde hace 20 años. EITiempo.com. Recuperado de https://www.eltiempo. com/justicia/investigacion/informe-de-la-contraloriasobre-la-crisis-en-las-carceles-287094 
The Legatum Institute. (2018). The Legatum Prosperity Index. Recuperado de https://www.prosperity.com/ rankings

Tobón, G. (2014). Del Estado benefactor al Estado penitenciario, la política social en el neoliberalismo. Forum, Revista Departamento de Ciencia Política, 2(5), 13-22. Recuperado de https://revistas.unal.edu.co/index. php/forum/article/view/48923

Torres, P. y Arias. G. (2011). La pedagogía crítica en la experiencia carcelaria de presas políticas. Revista Internacional de Investigación en Educación, 4(7), 27-43. Recuperado de https://revistas.javeriana.edu.co/ index.php/MAGIS/article/view/3554
Touraine, A. (2000). ¿Podremos vivir juntos?: Iguales y diferentes. México: Fondo de Cultura Económica.

Wacquant, L. (2010). Las cárceles de la miseria. Buenos Aires: Manantial.

Weber, M. (2014). Ensayos sobre metodología sociológica. Buenos Aires: Amorrortu.

Zaffaroni, E. (1998). Criminología, aproximación desde un margen. Bogotá: Temis.

Zemelman, H. (2007). El ángel de la historia: Determinación y autonomía de la condición humana. Barcelona: Anthropos. 


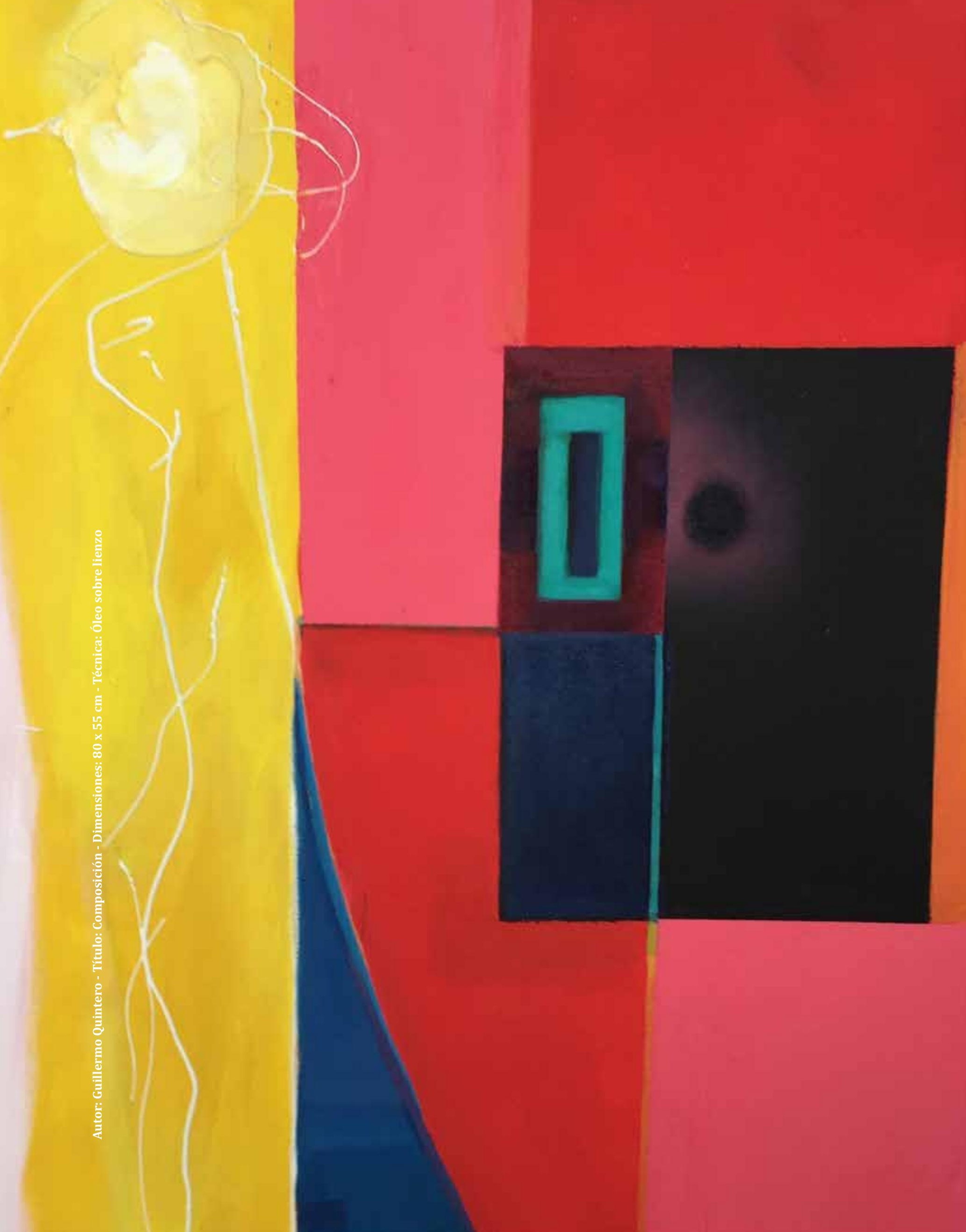

